\title{
A BIBLIOTECA CENTRAL DO CENTRO DE CIÊNCIAS DA SAÚDE DA UFRJ: MEMÓRIAS, IDENTIDADES E NARRATIVAS
}

\author{
Grasiele Barreto Rangel Monteiro \\ Mestre em Memória Social \\ Bibliotecária na Universidade Federal do Rio de Janeiro - UFRJ \\ grasielemonteiro@yahoo.com.br \\ Diana de Souza Pinto \\ Doutora em Psiquiatria, Psicanálise e Saúde Mental \\ Pesquisadora e docente no PPG em Memória Social \\ Universidade Federal do Estado do Rio de Janeiro (UNIRIO) \\ dianap@globo.com
}

\section{Resumo}

\begin{abstract}
Investiga as memórias e configurações identitárias profissionais e pessoais de funcionários da Biblioteca Central do Centro de Ciências da Saúde (CCS) da Universidade Federal do Rio de Janeiro (UFRJ), a partir de narrativas de experiências pessoais inseridas em uma entrevista grupal. Observa-se a coconstrução da interação localmente e suas relações com os contextos macro-estruturais que a permeiam. Parte-se do pressuposto de que as memórias, as narrativas e as configurações identitárias são construções sociais realizadas na interação, sendo, portanto, conceitos dinâmicos (LINDE, 2009). O corpus desta pesquisa é constituído por uma entrevista grupal com funcionários da biblioteca com base em perguntas abertas que visavam à evocação de narrativas que tematizassem as memórias em relação ao espaço. A análise da entrevista pauta-se na perspectiva interacional para a análise do discurso (GOFFMAN, 1979; GUMPERZ, 1982) e na Análise das Narrativas (RIESSMAN, 2008). A análise evidenciou o compartilhamento de experiências, a alta sintonia conversacional e o emprego de várias estratégias discursivas, tais como o diálogo construído (TANNEN, 1989). Observou-se, também, na construção da memória coletiva (HALBWACHS, 2004), diferentes alinhamentos (GOFFMAN, 1979) constitutivos de uma variada gama de identidades pessoais e profissionais, alicerçadas em valores tais como companheirismo, amizade e solidariedade.
\end{abstract}

Palavras-chave: Memória Social. Narrativa. Análise do discurso. Identidades. Sociolinguística Interacional.

\section{INTRODUÇÃO}

Iniciamos este artigo narrando uma estória $^{1}$ pessoal de uma das autoras que constituiu um dos fatores determinantes para

10 termo "estória", embora não seja reconhecido na ortografia oficial de língua portuguesa, foi uma escolha satisfatória neste estudo. Na tradução do texto de Linde (1993), o termo foi usado para designar estórias de vida e narrativas em diferentes contextos, distinguindo-se do conceito de história como uma sequência de relatos onde presume-se que são verdadeiros ou como disciplina. a investigação aqui desenvolvida.

Em 2008 a autora principal ingressou no corpo de servidores da Universidade Federal do Rio de Janeiro (UFRJ), lotada na Biblioteca Central do Centro de Ciências da Saúde (CCS). Foi recepcionada pelos funcionários dessa biblioteca com frases de boas vindas seguidas, muitas vezes, de comentários ou até mesmo de estórias sobre algo interessante, curioso ou inusitado ocorrido na biblioteca, mesmo não havendo uma pergunta direta que suscitasse tais declarações. No cotidiano, ela percebeu como os funcionários aparentavam ter prazer em 
narrar as suas experiências e como, de fato, essa biblioteca "tem estória para contar". Torna-se pertinente, neste momento, indicar um dos discursos mais reveladores da riqueza da memória dessa biblioteca "Ah... se essa biblioteca falasse...". Esta elocução, dita frequentemente pelo funcionário mais antigo da biblioteca à época, sempre fomentou curiosidade. Era como se houvesse algo para ser contado que não estava sendo dito, mas que ela precisava conhecer - embora compreenda hoje que não é possível conhecer, e sim construir - os sentidos dessa elocução.

Nosso objetivo, portanto, é compreender algo que em parte é efêmero: os instantes que perpassam as memórias constitutivas daquela instituição. A partir do enunciado acima, inferimos uma vontade de partilhar aquelas estórias, de dar-lhes visibilidade.

A Biblioteca Central do CCS foi criada em 1973 na Cidade Universitária, Ilha do Fundão. A coleção desta biblioteca é, em parte, proveniente de diversas unidades acadêmicas e administrativas transferidas para o Campus Universitário. Seu acervo é extenso e variado. Atende aproximadamente 3.000 usuários cadastrados fisicamente por ano e possui trinta e quatro funcionários concursados e seis funcionários terceirizados ${ }^{2}$. A partir da base Minerva (base de dados utilizada pelas bibliotecas da UFRJ) e do portal de periódicos (Coordenação de Aperfeiçoamento de Pessoal de Nível Superior (CAPES), os usuários podem pesquisar quais títulos a biblioteca possui. O seu acervo é parte substancial da identidade e da memória das ciências da saúde no Brasil, principalmente na área de medicina e representa uma memória viva $^{3}$ sobre a trajetória e o desenvolvimento

2 Fontes: UNIVERSIDADE FEDERAL DO RIO DE JANEIRO. Biblioteca Central do Centro de Ciências da Saúde, 2017. Disponível em: $\langle$ http://acd.ufrj.br/bibccs/ >. Acesso em: 25 abr. 2017.

UNIVERSIDADE FEDERAL DO RIO DE JANEIRO. Biblioteca Central do Centro de Ciências da Saúde. Sistema de Bibliotecas e Informação. Divisão de Desenvolvimento de Bibliotecas. Relatório. Base Gerencial - BAGER 2015. Rio de Janeiro, 2015.

3 Ver NEVES, Margarida de Souza. Lugares de Memória da Medicina no Brasil. Disponível em: $<$

http://www.historiaecultura.pro.br/cienciaepreconc da área da saúde no Brasil.

Considerando que as práticas sociais são constitutivas da memória e construídas discursivamente, este estudo insere-se no campo interdisciplinar da Memória Social, tomada aqui como um constante embate entre lembrar e esquecer. A seletividade relativa ao que lembrar e ao que esquecer orienta, assim, as discussões sobre as ações resultantes a esta tensão que lhe é constitutiva (GONDAR, 2016).

Este artigo ${ }^{4}$ objetiva investigar, a partir das narrativas de funcionários da Biblioteca Central do CCS/UFRJ, a memória social desta instituição e as configurações identitárias performatizadas (RIESSMAN, 2008) por seus funcionários, coconstruídas ao longo da entrevista que constitui o corpus. A análise pressupõe que as memórias, as narrativas e as identidades são construções sociais atualizadas na interação, ou seja, ao narrar estórias no presente para uma dada audiência, atuamos como personagens delas, projetando discursivamente dadas configurações identitárias. Nessa perspectiva, ações passadas são atualizadas no momento da interação, provocando uma fusão entre passado e presente.

Nesse contexto, as questões que nos orientam são: Como os funcionários coconstroem as memórias por meio das narrativas? Como se dá o embate entre lembrar e esquecer? Quais projeções discursivas são projetadas, ratificadas e modificadas ao longo da interação?

\section{ASPECTOS METODOLÓGICOS}

Esse estudo de caráter qualitativo cujo corpus de pesquisa é composto de uma entrevista grupal, baseada em um roteiro previamente definido, constituído por perguntas abertas realizadas pelas autoras do artigo com nove funcionários concursados da biblioteca, sendo três homens e seis mulheres. Todos os participantes trabalham ou trabalharam na Biblioteca Central do CCS há

eito/lugaresdememoria.htm>. Acesso em: 15 fev. 2017.

4 Integra a pesquisa de mestrado desenvolvida no âmbito da linha de Pesquisa Memória e Linguagem do Programa de Pós-graduação em Memória Social/UNIRIO. 
mais dez anos. $\mathrm{O}$ servidor mais antigo era Juca, na ocasião, com 38 anos de serviço na biblioteca. Jair, Bianca e Cecília entraram no mesmo concurso, todos com 17 anos de serviço na biblioteca. Já Geovana e Iara tinham 29 e 16 anos de serviço respectivamente. A duração do grupo focal, gravado em áudio, foi de uma hora e doze minutos $^{5}$. Para evitar interrupções e barulhos externos, o encontro foi realizado na sala de processamento técnico de livros, localizada no conjunto de seções internas da Biblioteca Central do CCS, cujo acesso é restrito, sendo permitida apenas a entrada de funcionários e pessoas autorizadas.

\section{APORTE TEÓRICO: A TRÍADE MEMÓRIA, IDENTIDADES E NARRATIVAS NA VERTENTE SOCIO- INTERACIONAL}

Concebemos a memória social como um conceito ético e político, que ultrapassa a esfera representável, abrangendo gestos, práticas, ações políticas etc. e, fundamentalmente, como um fenômeno social construído coletivamente (GONDAR, 2016). Nesse sentido, a memória pensada no presente evoca o passado em função de uma intencionalidade quanto ao porvir.

Segundo Linde (2009) integram as estórias de vida individuais outros sujeitos, que eventualmente, participaram direta ou indiretamente do evento narrado, podendo expor opiniões ou definir de forma distinta esse evento.

\subsection{A MEMÓRIA SOCIAL}

A concepção de Halbwachs (2004) sobre a construção social da memória pressupõe que as lembranças sempre provêm de um tempo, um local e de um compartilhamento por outras pessoas. Nesse sentido, podemos

5 A transcrição foi feita de acordo com as convenções listadas no Anexo A. Destacamos que a pesquisa foi submetida e aprovada pelo comitê de ética em pesquisa da UNIRIO. A fim de preservar as identidades e o caráter confidencial dos sujeitos envolvidos na pesquisa, todos os nomes dos participantes do grupo focal foram substituídos por pseudônimos. conceber que na projeção das lembranças estamos sempre em interação com uma rede de sentidos que organizam e dão coerência na construção das memórias. Tais sentidos são atravessados pelas janelas éticas, políticas e institucionais durante a interação, momento em que várias memórias são negociadas e compartilhadas entre os interlocutores. Halbwachs (2004) aponta que mesmo quando se trata de eventos vividos ou vistos apenas pelo indivíduo, essas lembranças permanecem coletivas à medida que as memórias individuais são constituídas por "quadros" que integram o meio social.

Segundo o autor, lembrar-se, para o indivíduo, é reconstruir seu passado partindo dos quadros sociais presentes de seu grupo. Não podemos reconstituir o passado, mas reconstruí-lo a partir de nossa visão do mundo presente, daquilo que permanece presente em um grupo da memoria desse tempo. Os quadros são constituídos de lembranças estáveis, dominantes e servem de ponto de fixo de organização durante um longo tempo. A lembrança assim está inserida na esfera social, pois o que faz o indivíduo lembrar é a sociedade, já que induz a evocação dessas lembranças em circunstâncias diferenciadas.

Destacamos que Halbwachs (2004) não desconsidera a existência da memória individual, mas declara que em interação com o social, a memória do indivíduo está atrelada a diferentes contextos e a vários participantes. Quando os acontecimentos são partilhados pelo grupo, a memória deixa de ser individual para tornar-se uma memória coletiva. Assim, a memória do indivíduo é constituída pelas memórias dos diversos grupos de que ele participa e é influenciado. Além disso, a memória individual só funciona porque o indivíduo utiliza as palavras e as ideias, frutos da sociedade, ou seja, instrumentos que ele não inventou, mas que se apropria para construir sua memória.

Os pressupostos de Halbwachs (2004) sobre construção coletiva da memória amparam a investigação de como os participantes da entrevista, que compõe o corpus deste trabalho, coconstróem as memórias relativas à biblioteca por meio de narrativas. $\mathrm{O}$ compartilhamento de lembranças, mesmo aquelas não experenciadas diretamente por alguns dos participantes, é uma característica frequente 
nas narrativas dos funcionários. Segundo Pollak (1992) existem alguns elementos constitutivos da memória, tanto individual quanto coletiva, tais como os acontecimentos, as pessoas ou personagens e os lugares. Os acontecimentos podem ser vividos pessoalmente ou "vividos por tabela", ou seja, aqueles de que a pessoa nem sempre participou, mas cuja importância é crucial para o grupo ou coletividade a ponto de a pessoa sentir-se como se ela tivesse, de fato, participado daqueles acontecimentos.

\subsection{A VERTENTE SOCIO- \\ INTERACIONISTA PARA A ANÁLISE DO DISCURSO}

De acordo com Bastos e Santos (2013), a arte de ouvir e contar histórias exerce fascínio nas diversas sociedades através dos séculos. $\mathrm{O}$ desenvolvimento das tecnologias de comunicação, somadas a mudanças relacionadas à concepção do sujeito, contribuíram para a evolução nas práticas de entrevistas com propósitos e funções diversos. $\mathrm{Na}$ visão tradicional, a entrevista é utilizada para coletar dados sobre os entrevistados. Neste sentido, o entrevistado funcionaria como um repositório de informações que devem ser extraídas pelo entrevistador (GUBRIUM; HOLSTEIN, 2003). Em uma perspectiva contemporânea, a entrevista passa a ser entendida como uma prática social, na qual entrevistado e entrevistador cooperam na constituição daquele encontro face-a-face. Nesse sentido, o foco da análise se concentra no processo contínuo de construção de subjetividades dos participantes.

A Sociolinguística Interacional considera cada um dos "pequenos momentos da interação face a face como cenários de construção do significado social e da experiência, passíveis de análise e de interesse sociológico e linguístico" (RIBEIRO; GARCEZ, 2002, p. 7). A preocupação central é analisar uma comunicação situada na interação face a face. Assim, o discurso, para a Sociolinguística Interacional, é concebido como uma coprodução conjunta dos participantes durante essa interação, sendo, portanto, o resultado de um esforço mútuo. Marcurschi (1986), ao discutir o conceito de interação conversacional, demonstra que a conversa "não se funda exclusivamente na produção individual de cada falante, mas na produção conjunta" (MARCUSCHI, 1986, p. 84), levando-nos a considerar a conversação como uma atividade de coprodução discursiva. Neste sentido, de acordo com Pinto (1995, p. 14), "poder-se-ia localizar aqui o surgimento da concepção de discurso tomada pela Sociolinguística Interacional enquanto $\mathrm{o}$ resultado de um esforço conjunto de seus participantes".

Para Gumperz (2002), a análise das convenções de contextualização, a exemplo do tom de voz, da linguagem não verbal, da ênfase em uma dada palavra, entre outros sinais, permite ao analista compreender como os participantes de uma interação sinalizam as pressuposições contextuais relevantes em um dado momento da interação. A conjugação das falas com as matrizes sócio culturais nas quais os discursos são construídos possibilitanos examinar da relação entre as formas linguísticas, o contexto de enunciação e o contexto macro. Mishler (2000) destaca que a investigação de como e por que as estórias são contadas permitem-nos inferir os processos de performances identitárias que se dão no discurso.

Os conceitos de footing, enquadre, alinhamento, convenções ou pistas de contextualização, apresentados nas próximas seções, nos orientarão na análise das performances identitárias dos participantes durante a interação, com foco especial no exame das narrativas a partir da perspectiva interacional.

\subsubsection{Enquadres, Footings e Convenções de Contextualização}

O termo enquadre “[...] situa a metamensagem contida em todo enunciado, sinalizando o que dizemos ou o que fazemos, ou como interpretamos o que é dito e feito" (GOFFMAN, 1979, p. 107). Em qualquer encontro face a face, os participantes estão permanentemente propondo ou mantendo enquadres, que organizam e orientam o discurso em relação à situação interacional. Posteriormente, em 1979, como um desdobramento do conceito de enquadre no discurso, Goffman introduziu o conceito de footing, passando a caracterizar o aspecto dinâmico do enquadre. O "footing representa 
o alinhamento, a postura, a posição, a projeção do "eu" de um participante na sua relação com o outro, consigo próprio ou com o discurso em construção" (GOFFMAN, 1979 , p. 107). São sinalizados através do modo como os participantes gerenciam a produção e a recepção das elocuções e podem indicar aspectos pessoais e sociais. Durante a interação os footings são introduzidos, negociados, ratificados (ou não), cosustentados e modificados. Tais mudanças são inerentes à fala natural e implicam, segundo Goffman, uma mudança no alinhamento que assumimos para nós e para os outros presentes, expressando o modo como conduzimos a produção ou a recepção de uma elocução.

As convenções de contextualização são "[...] pistas de natureza sociolinguística que utilizamos para sinalizar os nossos propósitos comunicativos ou inferir os propósitos conversacionais do interlocutor" (GUMPERZ, 1982, p. 149). Assim, de acordo com Ribeiro e Garcez (2002), existem as pistas linguísticas (por exemplo, alternância de idioma, de dialeto ou de estilo), pistas paralinguísticas (por exemplo, a sobreposição, o valor das pausas, o tempo da fala, as hesitações) e/ou pistas prosódicas (por exemplo, a entonação, o acento, a ênfase, o tom), constituídas de vários (sub)sistemas de sinais estabelecidos culturalmente. Podem ocorrer pistas não verbais, como direcionamento do olhar, o distanciamento entre os interlocutores, a presença de gestos, mudança de postura etc.

\subsection{AS IDENTIDADES NO DISCURSO}

Halbwachs (2004) sugere que a memória é um importante veículo na construção de identidades. Para Pollak (1992) a memória é um elemento que constitui um sentimento de identidade individual ou coletiva, pois ela impulsiona um sentimento de coerência e de continuidade tanto de um indivíduo como de um grupo na sua própria reconstrução. Utilizamos, nesta pesquisa, o conceito de identidades no plural, pois acreditamos que elas são constantemente atualizadas na interação. Destaca-se que Pollak (1992) já observara o anti-essencialismo desse conceito à medida que afirma que "memória e identidade podem perfeitamente ser negociadas, e não são fenômenos que devam ser compreendidos como essências de uma pessoa ou de um grupo" (POLLAK, 1992, p. $5)$.

Desse modo, de acordo com Fabrício e Lopes (2002), as narrativas pessoais são consideradas verdadeiras performances de identidades. Elas se concretizam na relação dialógica entre o "eu" e o "outro". Sendo assim, "nossa fabricação identitária é um processo intersubjetivo, dialógico e relacional, pois os efeitos de sentido criados estão sempre submetidos ao olhar do outro, sendo afetados pelo contexto emergente" (FABRÍCIO; LOPES, 2002, p. 17). Para os autores, os contextos institucionais são repletos de experiências de vida e, também, profissionais que fazem parte de uma trama identitária.

Fabrício e Lopes (2002) refletem sobre a inexistência de um princípio de identidade desvinculado de uma prática coletiva e de um determinado contexto social que lhe dê sentido (MARCONDES, 1997 apud FABRÍCIO; LOPES, 2002). Esses autores apoiam-se em teorias socioconstrucionistas do discurso e das identidades sociais e mostram que, à medida que novas possibilidades identitárias entram em ação no mundo contemporâneo, pressionando as identidades conhecidas a engajarem-se com a diferença, o entendimento dos processos identitários torna-se ainda mais complexo. Segundo esses autores, Foucault (1979) e Goffman (1979) trazem uma compreensão de como as narrativas na contemporaneidade constroem efeitos de sentido e de que forma elas colaboram no projeto identitário.

Com base em Foucault (1979 apud FABRÍCIO; LOPES, 2002), como não é possível pensar a vida social ou identidades sociais de forma descontextualizada, ainda mais porque elas sempre estão atravessadas pelas relações de poder, não é possível pensar em identidade única e homogênea. Assim, a concepção do significado e da vida social de forma unidimensional, homogênea e única foram substituídos por parâmetros da heterogeneidade e da diferença, visto que a linguagem é imprevisível, indeterminada, cujos efeitos de poder nos constroem de formas variadas. As identidades sociais são construções de validade contingencial e definidas por regras que atuam na linguagem. 
Nesse sentido, Fabrício e Lopes (2002) afirmam que a aparente homogeneidade das identidades sociais é operacional.

Para Fabrício e Lopes (2002), com relação à construção das identidades sociais, o socioconstrucionismo aponta para um contínuo envolvimento no processo de autoconstrução e também na construção dos outros. Dessa forma, construímos o outro ao mesmo tempo em que o outro nos constrói. Sendo seres sociais, estamos imersos constantemente no processo de vir a ser socialmente; isso significa que inexiste uma representação da essência de quem somos como apontara Pollak (1992) e corroborado nos estudos de Fabrício e Lopes (2002).

\subsection{A ANÁLISE DE NARRATIVAS NA PERSPECTIVA INTERACIONAL}

Ao longo de uma narrativa, como narradores, fazemos uma série de escolhas ao introduzir determinados cenários, personagens ou ações. Assim, conforme Schiffrin (2000 apud BASTOS 2005), ao criarmos esse "universo narrativo", estamos mostrando quem somos. As memórias são construídas por meio da seleção de lembranças. Nesse processo, há uma complexa relação entre a lembrança e o esquecimento, já que conforme afirma Gondar (2016) a memória e o esquecimento estão implicados.

A forma como contamos uma estória ou o seu conteúdo está, de certa forma, impregnado de identidades. "Compreendemos identidade como uma construção social, que envolve um processo dinâmico e situado de expor e interpretar quem somos, o relato de narrativas revela-se um lócus especialmente propício a essa exposição" (BASTOS, 2005, p. 81).

A visão da narrativa como uma prática social, sendo influenciada pela situação local e por uma ordem social mais ampla (BASTOS, 2005), tem se mostrado uma opção teórico-metodológica produtiva nos campos das Ciências Humanas e Sociais Aplicadas (BASTOS, 2005; PINTO, 2001, SCHIFFRIN, 1996, LINDE 1993, entre outros). Neste caso, é possível compreender, a partir das narrativas, quem somos bem como a dinâmica de nossa vida social. No que diz respeito a como experiência e relato se relacionam, na abordagem interacional, as experiências são coconstruídas durante a narrativa, sendo consideradas recontagens seletivas e contextualizadas das nossas lembranças.

Quando falamos, podemos utilizar vários recursos "poéticos" ou estratégias de envolvimento. Tais recursos estão mais presentes nos discursos de alguns falantes do que de outros. Tannen (1989) afirma que, quando $o$ falante emprega com maior frequência tais estratégias, ele utiliza o que a autora denomina de estilo conversacional de alto envolvimento. De acordo com a autora, as estratégias de envolvimento refletem e criam simultaneamente o envolvimento interpessoal. $\mathrm{O}$ envolvimento na interação implica que tanto falante quanto ouvinte respondam ativamente o que é transparecido na interação, através de sinais de envolvimento, seja diretamente através de palavras ou indiretamente através de gestos ou sinais não verbais similares. Gumperz (1982 apud TANNEN, 1989) afirma que o envolvimento conversacional é a base para todo o entendimento linguístico. No entanto, é necessário que as especificidades da língua e do conhecimento sócio-cultural sejam compartilhadas. Assim, segundo Gumperz, para que o envolvimento conversacional seja bem-sucedido é necessário que ocorra o processo de inferência conversacional, que é a habilidade de inferir o significado das elocuções dos outros participantes e as suas expectativas na interação.

Para Linde (2001) as narrativas auxiliam na preservação e memorização das técnicas e para a tomada de decisões dos gestores nas instituições. Elas podem também ser utilizadas como um caminho para as instituições lembrarem-se do seu passado e para compreenderem suas identidades e a de seus membros. Nesse sentido, as narrativas representam as instituições. Ao discorrer sobre o papel das narrativas nas instituições, a autora afirma que as narrativas têm a força de criar e reproduzir as identidades e a memória das instituições. Cabe destacar que a autora opta pelo termo instituição em detrimento do termo organização, posto que este sugere uma organização formal, enquanto aquele é mais abrangente, incluindo práticas e grupos sociais, que mantenham uma existência contínua. 


\section{ANALISE DAS NARRATIVAS}

O ponto de partida da entrevista deu-se através da elocução "Ah... se essa biblioteca falasse...”. Explicamos, na ocasião, que esta elocução fora algumas vezes repetida por um funcionário da biblioteca que, ao contar a uma das autoras, informalmente, algumas estórias daquela instituição, sempre a exclamava. As respostas iniciais relatavam que tal elocução se referia à história da biblioteca, aos diversos episódios marcantes ocorridos desde a sua fundação, à sua importância e, finalmente, às lembranças dos ex-alunos que passaram pela instituição.

Foi surpreendente descobrir que essa elocução, pronunciada várias vezes para, no nosso entendimento, evidenciar a riqueza da memória da instituição, se originou de episódios muito inusitados e curiosos que circulam sobre os encontros afetivos entre os estudantes nas antigas cabines de estudo da biblioteca.

Para efeitos da presente discussão, selecionamos dois segmentos do grupo focal.

Segmento 1

\begin{tabular}{|c|c|c|}
\hline 1 & Giane & $\begin{array}{l}\text { queria saber de vocês o que vocês acham que quer dizer isso, essa } \\
\text { afirmação, essa exclamação, ah... se essa biblioteca falasse.... }\end{array}$ \\
\hline 2 & Jair & [risos] \\
\hline & & peguei muitas vezes... muitas vezes peguei namorando violentamente. \\
\hline 3 & Jиса & $\dot{E}-$ \\
\hline 4 & Iara & [riso] \\
\hline & & $\begin{array}{l}\text { é é por isso, "ah se essa biblioteca falasse", as paredes iam ter muito } \\
\text { estória= }\end{array}$ \\
\hline 5 & Juca & $\begin{array}{l}\text { = as pessoas ali naqueles momentos de... livres...eles ficavam } \\
\text { namorando dentro das cabines. Várias vezes eu dei flagrante, os } \\
\text { outros rapazes que trabalhavam comigo também. E até- }\end{array}$ \\
\hline 6 & Delma & e como é que era para vocês se deparar com essa situação, assim? \\
\hline 7 & Geovana & já tava até normal, sabe. \\
\hline & & já tava uma coisa até normal \\
\hline 8 & Jair & eu já peguei situações. Situações indecentes, indecentes \\
\hline 9 & Delma & Indecentes \\
\hline 10 & Јиса & justamente, justamente \\
\hline 11 & Jair & pode falar? \\
\hline 12 & Delma & tem que falar \\
\hline 13 & Jair & com a saia levantada e na prática de sexo \\
\hline 14 & Geovana & $\begin{array}{l}\text { porque as cabines ficavam na parte de baixo e na parte de cima onde } \\
\text { só se você fosse para a cabine mesmo } \\
\text { que veria, entendeu? }\end{array}$ \\
\hline 15 & Iara & para estudar \\
\hline 16 & Geovana & $\begin{array}{l}\text { e tinha cabines, né Juca, que eles se davam ao luxo de pintar a porta } \\
\text { que era de vidro }\end{array}$ \\
\hline 17 & Jair & colocavam papel \\
\hline 18 & Јиса & colocavam papel \\
\hline
\end{tabular}

No turno 2 Jair amplia ainda mais o tópico sobre o namoro nas cabines. Utiliza a autorepetição "peguei muitas vezes... muitas vezes peguei" no seu discurso com o efeito de ritmação para provocar envolvimento através da estrutura de chiasma, que segundo Tannen (1989), é a repetição feita invertendo-se a ordem das palavras. Observe que os verbos "peguei", repetido nos turnos 2 e 8 pronunciado por Jair e "dei", completando o sentido de flagrante no turno 5 por Juca, nos dá indícios da mudança de alinhamento de Jair e Juca, pois nesse momento ambos, ao mesmo tempo, se alinham como responsáveis por guardar a integridade moral da biblioteca indo além das atribuições meramente administrativas, como, por exemplo, a guarda de livros. Quando Jair fala “... muitas vezes 
peguei namorando violentamente" (turno 2), Juca ecoa e reitera a fala de Jair com a expressão "é" (turno 3). O mesmo ocorre no discurso de Jair "eu já peguei situações. Situações indecentes, indecentes" (turno 8), o qual é ecoado por Juca em "justamente, justamente" (turno 10).

Delma pergunta para os participantes como era para eles viverem essa situação, referindo-se ao namoro nas cabines da biblioteca (turno 6). Geovana responde que era uma coisa comum, então Jair toma o turno e classifica as situações que ele presenciou nas cabines como sendo "indecentes", que tem seu sentido intensificado pela repetição, no turno 9. Podemos considerar que a função desta repetição cumpre o papel interacional de provocar envolvimento ao dar ênfase à categorização da situação que Jair irá narrar. Além disso, a escolha do termo indecente para qualificar a situação narrada por Jair é uma estratégia para intensificar o grau de transgressão de tais situações.

No turno 9, Delma repete o termo "indecentes" que pode ser classificado como um sinal de retroalimentação, estando no nível interacional da conversa (TANNEN, 1989). Em seguida, no turno 10, Juca repete o termo "justamente" cuja função pode ser interpretada no nível da produção do discurso, como transição e preenchimento de vazios durante a narrativa, o qual também é uma estratégia de envolvimento (TANNEN, 1989).

No turno 11, Jair convida o ouvinte a conhecer alguns dos episódios que ele caracteriza como "indecentes", porém antes ele pergunta para Delma se ele pode narrá-los. Esta pode ser uma estratégia para tornar a narrativa mais interessante à medida que causa uma série de expectativas no ouvinte em relação à estória. A permissão é concedida por Delma, que tem autoridade de pesquisadora/orientadora no estudo. É importante salientar que a mesma, durante o grupo focal, deixou os participantes à vontade para interagirem sem impor o papel de autoridade no discurso, que, no entanto, lhe é atribuído por Jair. Isso evidência a construção local, no discurso, de identidades que são coletivamente projetadas, ratificadas ou modificadas ao longo da interação, como já apontara Goffman (1979).

Após Jair introduzir a ação complicadora no seu discurso "com a saia levantada e na prática de sexo" (turno 13), nos turnos 14 a 18 , os outros participantes narraram como funcionavam as cabines, contribuindo com evidências que fornecem veracidade à narrativa de Jair. Algumas vezes as elocuções são repetidas por diferentes participantes, inclusive ao mesmo tempo, o que demonstra grande nível de sintonia entre eles, como por exemplo "colocavam papel" (turnos 17 e 18).

Geovana, no turno 14, oferece detalhes sobre como eram as cabines de estudo e como a estrutura física das cabines propiciava os episódios de sexo, o que é corroborado pelos demais participantes nos turnos 15 a 18 , nos quais observamos como a narrativa é coconstruída e como as memórias são compartilhadas.

\section{Segmento 2}

1 Giane e você Bianca, tem alguma coisa pra falar, como é que foi?

2 Bianca é... como Jair, Iara, também tenho 17 anos aqui, também concursada de de 92 e... a biblioteca teve assim certa influência é... forte, né? Porque quando eu vim pra cá minha

\section{[choro]}

filha tinha tava com 11 meses, então ela... é... (6.0) ela cresceu, né, aí no meio dessas estantes aí correndo. Quando tinha... tinha alguma coisa... é, algum evento né, aqui... ela gostava muito de vim pra cá, né-

[vários participantes com lágrimas]

3 Cecília e vem até hoje, né?

4 Iara é, os filhos foram criados bem dizer aqui

5 Bianca como Juca falou né, não crescemos mais por é... força de

6 Jair $\left[\begin{array}{r}\text { vontade mesmo, né? } \\ \text { [riu] } \\ \text { fazer a creche aqui }\end{array}\right.$ 
$\mathrm{O}$ segundo segmento foi o ponto mais emocionante e intrigante do grupo focal. É curioso observar os diferentes alinhamentos que se entrecruzam no discurso de Bianca. Ela começa se alinhando como funcionária ao relatar que trabalha na biblioteca há bastante tempo "também tenho 17 anos aqui" (turno 2), que é concursada "também concursada" (turno 2) e, em seguida, ao falar da influência da biblioteca em sua vida, se alinha como mãe "minha filha tava com 11 meses" (turno 2). Ela relata que a biblioteca teve "certa influência", e após uma hesitação, acrescenta dizendo que a influência foi forte "biblioteca teve assim certa influência é... forte, né?" (turno 2), expondo os motivos dessa importância através da figura materna "é... como Jair, Iara, também tenho 17 anos aqui, também concursada de 92 e... a biblioteca teve assim certa influência é... forte, né? Porque quando eu vim pra cá minha filha tinha tava com 11 meses, então ela... é... (6.0) ela cresceu, né, aí no meio dessas estantes aí correndo" (turno 2). É interessante observar como Bianca, ao trazer a filha para a narrativa, transforma a biblioteca em um espaço lúdico: "Ela cresceu, né, aí no meio dessas estantes, aí correndo. Quando tinha... tinha alguma coisa... é algum evento né aqui... ela gostava muito de vim pra cá" (turno 2). Neste caso, o espaço da biblioteca é apropriado pela filha de Bianca e ressignificado. Tanto para Bianca como para a sua filha, a biblioteca é narrada como um local que funciona como uma extensão da sua casa.

Bianca ficou tão emocionada ao descrever a importância da biblioteca na sua vida, no turno 2, que ficou cerca de seis segundos (6.0) sem conseguir falar e chorou ao narrar sobre quando ela ingressou na biblioteca, ocasião em que a sua filha tinha onze meses, com 17 anos no momento da entrevista.

Após contar que a sua filha cresceu na biblioteca, que participava dos eventos comemorativos, outra funcionária, também emocionada, conta que a filha de Bianca gosta de estar na biblioteca até hoje. Assim, ela presentifica o elo entre a funcionária, sua filha e a instituição. As várias hesitações no discurso de Bianca marcam como era profundo e importante o tópico de que ela estava tratando, de forma que ela tinha dificuldades de encontrar as palavras para construir a sua narrativa. Tal dificuldade não desvaloriza o seu desempenho como narradora, muito pelo contrário. Quando a emoção tomou a voz de Bianca, um silêncio tomou conta do espaço. Ninguém foi capaz de tomar o turno de Bianca mesmo após os seis segundos de silêncio. De acordo com o conceito de fillers (COULTHARD, 1981), as hesitações de Bianca também contribuíram para a sua permanência com o turno, pois demonstraram que ela não havia finalizado a elocução e havia o interesse em prosseguir.

Foi intrigante e surpreendente verificar que a pergunta sobre a importância da biblioteca, para a vida de Bianca, no primeiro turno, despertou aspectos tão pessoais.

Nas elocuções "é, os filhos foram criados bem dizer aqui" (turno 4) e "fazer a creche aqui" (turno 6), verificamos que outros funcionários compartilham uma experiência similar a de Bianca, visto que os dois elementos da relação família/trabalho parecem estar atrelados. Rollemberg (2013) reflete sobre as relações de pertencimento a partir dos estudos de Baker. De acordo com Baker (2001 apud ROLLEMBERG 2013), a construção conjunta entre entrevistado e entrevistador vai além de uma sequência de perguntas e respostas. Os relatos de experiência voltam a ser experimentados na entrevista, contribuindo para 0 estabelecimento de pertencimento em várias categorias identitárias. Acreditamos que essa construção da família na biblioteca contribui para os sentidos de um sentimento de pertencimento dos funcionários em relação à instituição.

\section{CONCLUSÃO}

Orientados pela concepção da memória como um conceito ético e político, que ultrapassa a esfera representável, abrangendo gestos, práticas, ações políticas etc., ou seja, como um fenômeno construído coletivamente, procedemos a analise das narrativas dos funcionários. Na construção da memória dessa instituição, os funcionários constantemente projetam e ratificam suas diferentes identidades no discurso. Daí a importância em conduzir os nossos questionamentos para além da fronteira "do 
que é dito" para o "como é dito". Assim, nossas reflexões foram conduzidas considerando as seguintes questões: como os funcionários coconstroem as memórias por meio das narrativas? Como se dá o embate entre lembrar e esquecer? Quais projeções discursivas são projetadas, ratificadas e modificadas ao longo da interação?

Com base na investigação de como os funcionários coconstroem suas memórias no discurso, observamos o compartilhamento de experiências, a alta sintonia conversacional e o emprego de várias estratégias discursivas, as quais são capazes de criar coerência e envolvimento interpessoal no discurso. Isso ocorre, por exemplo, com o uso das repetições em suas diferentes formas, o alongamento de vogais, como, por exemplo, a fonologia expressiva, e os discursos direto e indireto - ou diálogo construído. Tais estratégias integram a natureza dialógica da linguagem, configurando, assim, a conversa como uma produção conjunta entre os participantes (TANNEN, 1989).

Intrínseca ao processo de construção conjunta da memória há o embate entre lembrar e esquecer, conforme uma das proposições de Gondar (2016) na qual a autora reflete que a memória implica o esquecimento. As estruturas de sentimento, experiência e percepção transformadas em lembranças pelos funcionários e aquelas relegadas ao esquecimento estão presentes na construção dessas memórias e subjaz o discurso dos funcionários à medida que há uma intencionalidade nessa seleção. Assim, a análise dos dados foi pautada no resultado de uma relação complexa e paradoxal.

$\mathrm{Na}$ investigação sobre como as identidades são projetadas, ratificadas e modificadas discursivamente ao longo da entrevista grupal, observamos diferentes alinhamentos (GOFFMAN, 1979) na construção da memória coletiva, os quais oscilam entre identidades pessoais e profissionais. Desse modo os funcionários apresentam o privilégio e a satisfação dos funcionários por trabalharem na biblioteca e a ressignificação do seu espaço como extensão do espaço familiar, a medida que a família também participava, com frequência, da rotina da biblioteca para fins distintos daqueles para a qual a instituição se propõe.

Fazer esta pesquisa é estabelecer, grosso modo, uma ponte entre passado e presente. Acreditamos que o conhecimento da memória desta instituição pode servir como ponto de apoio para os diferentes agentes sociais que nela atuam, visto que os resultados que emanam desse olhar podem contribuir para uma maior legitimação institucional.

\title{
CENTRAL LIBRARY OF THE CENTER FOR HEALTH SCIENCES OF UFRJ: MEMORIES, IDENTITIES AND NARRATIVES
}

\begin{abstract}
Examines the professional and personal memories as well as identity configurations of employees of the Central Library of the Center for Health Sciences/Federal University of Rio de Janeiro based on personal experience narratives contained in a group interview. The local coconstruction of the interaction and its relationships with the macro-structural contexts permeating it were observed. The study was founded on the assumption that memories, narratives and identity configurations are social constructions built during
\end{abstract}


interactions, and therefore are dynamic contexts (LINDE, 2009). The corpus of this study is a group interview with the library employees. The interview consisted of open questions designed to evoke narratives involving memories of the library. The analysis of the interview was guided by the interactional perspective on discourse analysis (GOFFMAN, 1979; GUMPERZ, 1982) and by Narrative Analysis (RIESSMAN, 2008), and it revealed shared experiences, highly tuned conversations and the use of several discourse strategies such as constructed dialogue (TANNEN, 1989). Different alignments (GOFFMAN, 1979) consisting of a wide range of personal and professional identities based on values such as comradeship, friendship and solidarity were also observed during the construction of the collective memory (HALBWACHS, 2004).

Keywords: Social memory. Narrative. Discourse analysis. Identities. Interactional sociolinguistics.

\section{REFERÊNCIAS}

BAKHTIN, Mikhail. Marxismo e filosofia da linguagem. São Paulo: Hucitec, 1986.

BASTOS, Liliana Cabral. Contando estórias em contextos espontâneos e institucionais: uma introdução ao estudo da narrativa. Calidoscópio, S. Leopoldo, v.3, n.2, p.74-87, 2005.

BASTOS, Liliana Cabral; SANTOS, William Soares. A entrevista na pesquisa qualitativa: perspectivas em análise da narrativa e da interação. Rio de Janeiro: Quartet, 2013. p. 9-20.

GOFFMAN, Erving. A situação negligenciada. Tradução de Pedro M. Garcez. In. RIBEIRO, B. T.; GARCEZ, P. M. (Org.). Sociolinguística interacional. 2. ed. São Paulo: Loyola, 2002. p. 13-20. Tradução de: The neglected situation, 1964.

GOFFMAN, Erving. Footing. Tradução de Beatriz Fontana. In. RIBEIRO, B. T.; GARCEZ, P. M. (Org.). Sociolinguística interacional. 2. ed. São Paulo: Loyola, 2002. p. 107-148.

Tradução de: Footing, 1979.

GONDAR, Jô. Quatro proposições sobre memória social. In: GONDAR, Jô; DODEBEI, Vera. (Org.). O que é memória social? Rio de Janeiro: Contra Capa, 2005. p. 11-26.

GONDAR, Jô. Cinco proposições sobre memória social. In: DODEBEI, Vera; FARIAS, Francisco; GONDAR, Jô. (Org.). Por que memória social? Revista Morpheus, Rio de Janeiro, v.9, n.15, 2016.

GUBRIUM, Jaber F., HOLSTEIN, James A.
Postmodern Sensibilities. In:

Postmodern Interviewing. Gubrium J. F., Holstein, J. A. (Org.). Thousand Oaks, CA: Sage, 2003. p. 3-18.

GUMPERZ, John Joseph. Convenções de contextualização. Tradução de José Luiz Meurer; Viviane Heberle. In. RIBEIRO, B. T.; GARCEZ, P. M. (Org.). Sociolinguística interacional. 2. ed. São Paulo: Loyola, 2002. p. 149-182. Tradução de: Contextualization conventions, 1982.

HALBWACHS, Maurice. A memória coletiva e a memória individual. In: A memória coletiva. São Paulo: Centauro, 2004. p. 29-56. HALBWACHS, Maurice. Les cadres sociaux de la mémoire. Paris: Alcan, 1925.

LE GOFF, Jacques. Memória. In:

História e Memória. Campinas: Unicamp, 2003. p.422-476.

LINDE, Charlotte. Narrative in institutions. In: . The handbook of discourse Analysis.

Oxford: Blackwell, 2001. p. 518-535.

LINDE, Charlotte. How institutions remember. In: Working the past: Narrative and institutional memory. New York: Oxford University Press, 2009. p. 3 - 14.

LINDE, Charlotte. Life stories: the creational of coherence. New York: Oxford University Press, 1993.

MARCUSCHI, Luiz Antônio. Análise da conversação. Rio de Janeiro: Ática, 1986.

MISHLER, Elliot George. Narrativa e identidade: a mão dupla do tempo. In: LOPES, 
Luiz Paulo da Moita; BASTOS, Lilian Cabral (Org.). Identidades: recortes multi e interdisciplinares. Campinas: Mercado das letras, 2002. p. 97-119.

NEVES, Margarida de Souza. Lugares de Memória da Medicina no Brasil. Disponível em: <

http://www.historiaecultura.pro.br/cienciaepreco nceito/lugaresdememoria.htm>. Acesso em: 15 fev. 2017.

NORA, Pierre. Entre memória e história: a problemática dos lugares. São Paulo, Projeto

História - Revista do Programa de Estudos Pós graduados em História e do departamento de História. V. 10, 1993.

PINTO, Diana de Souza. A percepção da loucura: análise do discurso de pacientes internadas numa Instituição Psiquiátrica. 1995. 163 f. Dissertação (Mestrado em Linguística) Universidade Federal do Rio de Janeiro, Rio de Janeiro, 1995.

PINTO, Diana de Souza. As estórias de Larissa: o processo de construção da referência e as múltiplas "projeções do eu" em narrativas em uma entrevista psiquiátrica. In: RIBEIRO, B. T.; LIMA, C. C.; DANTAS, M. T. L. (Org.). Narrativa, Identidade e Clínica. Rio de Janeiro: Edições IPUB - CUCA, 2001. p. 121141.

POLLAK, Michael. Memória e identidade social. In: Estudos históricos, Rio de Janeiro, vol. 5, n. 10, 1992. p. 200-212.

RIBEIRO, Branca T. Coherence in Psychotic Discourse. New York: Oxford University Press, 1994.
RIBEIRO, Branca Telles; GARCEZ, Pedro Moraes. (Org.). Apresentação à nova edição. In. Sociolinguística Interacional. 2. ed. São Paulo: Loyola, 2002. p. 7-11.

RIESSMAN, Catherine Kohler. Narrative Methods for the Human Sciences. California: Sage Publications, 2008.

ROLLEMBERG, Ana Tereza Vieira Machado. Entrevistas de pesquisa: oportunidades de coconstrução de significados. In: BASTOS, Liliana Cabral; SANTOS, William Soares. A entrevista na pesquisa qualitativa: perspectivas em análise da narrativa e da interação. Rio de Janeiro: Quartet, 2013. p. 37-46.

SANTOS, William Soares. Níveis de interpretação na entrevista de pesquisa interpretativa com narrativas. In: BASTOS, Liliana Cabral; SANTOS, William Soares. A entrevista na pesquisa qualitativa: perspectivas em análise da narrativa e da interação. Rio de Janeiro: Quartet, 2013. p. 21-35.

SCHIFFRIN, Deborah. Narrative as self-portrait: sociolinguistic constructions of identity.

Language in Society, v.25, n. 2, p.167-203, 1996.

TANNEN, Deborah. Talking voices: repetition, dialogue, and imagery in conversational discourse. 3. reimp. New York: Press Syndicate of the University of Cambridge, 1989.

UNIVERSIDADE FEDERAL DO RIO DE JANEIRO. Biblioteca Central do Centro de Ciências da Saúde, 2009. Disponível em: < http://acd.ufrj.br/bibccs/>. Acesso em: 20 set. 2009.

\section{ANEXO A - Convenções de Transcrição}

\begin{tabular}{|c|l|}
\hline SÍMBOLO & \multicolumn{1}{c|}{ ESPECIFICAÇ̃̃O } \\
\hline.. & Pausa observada ou quebra no ritmo da fala com menos de meio segundo \\
\hline$\ldots$ & Pausa observada de meio segundo ou mais \\
\hline. & Descida leve, sinalizando o final da elocução \\
\hline$?$ & Subida rápida, sinalizando uma interrogação \\
\hline, & Subida leve, sinalizando que mais fala virá \\
\hline
\end{tabular}




\begin{tabular}{|c|l|}
\hline- & Parada súbita devido à interrupção \\
\hline$(\quad)$ & Fala não compreendida \\
\hline$(0,0)$ & Indicação dos segundos de pausa durante a elocução \\
\hline$[\quad]$ & $\begin{array}{l}\text { Observações não verbais observadas pelas entrevistadoras durante a } \\
\text { entrevista }\end{array}$ \\
\hline[ & Duas elocuções ligadas por este sinal indicando sobreposição das falas \\
\hline Sublinhado & Enfase \\
\hline
\end{tabular}

Fonte: Ribeiro (1994). Convenções de Transcrição. 